\title{
Angiotensin and Thromboxane in the Enhanced Renal Adrenergic Nerve Sensitivity of Acute Renal Failure
}

John B. Robinette and John D. Conger

Department of Medicine, University of Colorado Health Science Center, Veterans Administration Medical Center, Denver, Colorado 80220

\begin{abstract}
The roles of intrarenal angiotensin (A) and thromboxane (TX) in the vascular hypersensitivity to renal nerve stimulation (RNS) and paradoxical vasoconstriction to renal perfusion pressure (RPP) reduction in the autoregulatory range in 1 wk norepinephrine (NE)-induced acute renal failure (ARF) in rats were investigated. Renal blood flow (RBF) responses were determined before and during intrarenal infusion of an AII and TXA 2 antagonist. Saralasin or SQ29548 alone partially corrected the slopes of RBF to RNS and RPP reduction in NEARF rats $(P<0.02)$. Saralasin + SQ29548 normalized the RBF response to RNS. While combined saralasin + SQ29548 eliminated the vasoconstriction to RPP reduction, similar to the effect of renal denervation, appropriate vasodilatation was not restored. Renal vein norepinephrine efflux during RNS was disproportionately increased in NE-ARF $(P<0.001)$ and was suppressed by saralasin + SQ29548 infusion $(P<0.005)$.

It is concluded that the enhanced sensitivity to RNS and paradoxical vasoconstriction to RPP reduction in 1 wk NEARF kidneys are the result of intrarenal TX and AII acceleration of neurotransmitter release to adrenergic nerve activity. (J. Clin. Invest. 1990. 86:1532-1539.) Key words: vascular hypersensitivity $\bullet$ renal nerve stimulation
\end{abstract}

\section{Introduction}

Clinical and laboratory evidence indicates that basal renal blood flow $(\mathrm{RBF})^{1}$ returns to $>40 \%$ of normal in the maintenance phase of ischemic acute renal failure (ARF) (1-3). However, experimental studies have shown that the stimulated reactivity of the renal vasculature to neurohormonal agents is abnormal in this setting. In both the renal artery clamp and norepinephrine models of ARF there is a loss of the normal $\mathrm{RBF}$ autoregulatory response to a reduction in renal perfusion pressure (RPP) (4-6). In addition, in the latter model there is a paradoxical vasoconstriction to RPP reduction and hypersensitivity to renal nerve stimulation (RNS) (7). The hypersensitivity to RNS coupled with the observation that renal denerva-

Address correspondence to John D. Conger, M.D., V. A. Medical Center, 1055 Clermont St., $111 \mathrm{C}$, Denver, CO 80220. 1990.

Received for publication 7 April 1989 and in revised form $17 \mathrm{July}$

1. Abbreviations used in this paper: AII, angiotensin II; ARF, acute renal failure; EMF, electromotive force; MAP, mean arterial pressure; NE, norepinephrine; RBF, renal blood flow; RNS, renal nerve stimulation; RPP, renal perfusion pressure; RVR, renovascular resistance; TXB, thromboxane.

The Journal of Clinical Investigation, Inc. Volume 86, November 1990, 1532-1539 tion corrects the paradoxical vasoconstriction to RPP reduction suggests that increased sensitivity to renal adrenergic nerve activity may be related to the aberrant response to reduction in RPP (7).

The mechanism of hypersensitivity to RNS, and presumed exaggerated vascular response to spontaneous renal adrenergic nerve activity, in ischemic ARF is unknown. However, several studies have demonstrated that both angiotensin and thromboxane can augment the vasoconstrictor response to RNS $(8-12)$. Whereas the enhancing property of either angiotensin or thromboxane is not fully understood, it appears to be more than a simple additive pressor effect because it can be induced with subpressor doses and is not similarly observed with intravascular norepinephrine infusion $(8-10,12)$.

The possibility that angiotensin and/or thromboxane may be responsible for the hypersensitivity to adrenergic nerve stimulation in ischemic ARF is supported by experimental studies that have demonstrated increases in both hormones after ischemic injury. Hayes et al. (13) and DiBona and Sawin (14) have shown that renal renin activity is elevated and Hatziantoniou and Papanikolaou (15) have shown increases in urinary thromboxane $\mathrm{B}_{2}\left(\mathrm{TXB}_{2}\right)$ excretion in ischemic ARF models.

In the present study it was proposed that the increased vascular sensitivity to renal adrenergic nerve activity, as manifest experimentally by a hypersensitivity to RNS, was due to the enhancing effect of increases in intrarenal angiotensin and/or thromboxane. To examine this hypothesis, we measured $R B F$ responses to RNS and RPP reduction in ischemic $A R F$ and control rats before and after infusion of competitive antagonists of angiotensin II (AII) and thromboxane $\mathrm{A}_{2}$ $\left(\mathrm{TXA}_{2}\right)$ alone or in combination. The results were compared to those observed before and after renal denervation. To determine if the effects of AII and TX inhibition were mediated through a reduction in adrenergic neurotransmitter release, changes in renal vein norepinephrine were measured before and during RNS.

\section{Methods}

The disease model, NE-induced ARF, has been described previously (2). Briefly, adult Sprague-Dawley rats weighing 250-300 g underwent right nephrectomy $10 \mathrm{~d}$ before disease induction. After pentobarbital anesthesia, the left renal pedicle was exposed and NE was delivered at $0.6 \mu \mathrm{g} / \mathrm{kg} \cdot \mathrm{min}^{-1}$ for $90 \mathrm{~min}$ into the renal artery. The rats were returned to metabolic cages receiving water ad lib and a low-potassium diet (ICN Pharmaceuticals, Cleveland, $\mathrm{OH}$ ) for $72 \mathrm{~h}$ and a standard rat chow diet (Wayne Feed, Longmont, $\mathrm{CO}$ ) thereafter. Peak azotemia occurred between 24 and $48 \mathrm{~h}$ after NE infusion. Renal blood flow returned to $70 \%$ of control levels by $24 \mathrm{~h}$ and rose to control levels by 1 wk. Inulin clearance $\left(C_{\mathrm{IN}}\right)$ fell to zero after NE infusion and slowly rose to $40 \%$ of control at $1 \mathrm{wk}(16)$.

The technique of measuring renal vascular reactivity was described 
previously (7) and carried out as follows: At $1 \mathrm{wk}$, the left kidney was exposed through a flank incision under pentobarbital anesthesia, the renal artery dissected bluntly from the renal vein, and a catheter placed in the ureter. Mean arterial pressure (MAP) was measured through a femoral artery catheter, which was connected to an electronic transducer (P23Db; Statham Instruments, Oxnard, CA), and a direct-writing recorder (model 7702B; Hewlett-Packard Co., Palo Alto, CA). Ringer's lactate, containing an amount of inulin sufficient to give plasma concentrations of $50-100 \mathrm{mg} / \mathrm{dl}$, was infused at $2 \mathrm{ml} / \mathrm{h}$ through the jugular venous catheter. A micropipette (OD $35 \mu \mathrm{m}$ ) was positioned in the renal artery as during ARF induction. Ringer's lactate was infused at $2 \mu \mathrm{l} / \mathrm{min}$. After $1 \mathrm{~h}$ of equilibration, blood and urine samples were collected for $C_{\mathrm{IN}}$ measurements. The effects of RNS on $\mathrm{RBF}$ were then measured. The left renal nerve bundle was isolated near the aorta, crushed centrally, and placed over a small insulated stainless steel hook electrode for nerve stimulation with a stimulus isolation unit (model SIU5, Grass Instrument Co., Quincy, MA). The nerve bundle was isolated by surrounding it with a Parafilm sheet for a distance of $1 \mathrm{~cm}$. Stimulator settings were as follows: electromotive force (EMF) $3 \mathrm{~V}$, duration $50 \mathrm{~ms}$, delay $50 \mathrm{~ms}$. Frequency of stimulation was from 0 to $10 \mathrm{~Hz}$ at $2-\mathrm{Hz}$ intervals carried out in a random manner. The EMF used in these experiments was submaximal. In separate rats EMF producing maximal response was between 5 and 10 $V$. While less than ideal because of uncertainty regarding completeness of nerve fiber depolarization, the submaximal voltage was used for the following reasons: Stimulation at maximal or supramaximal voltage even at low frequencies caused nerve fatiguing after more than three separate stimulations, caused interference with electromagnetic flow probe measurement of RBF, and submaximal voltage was assumed to depolarize at least a constant number of nerve fibers in any single RNS experiment such that the results would be valid when comparisons were made before and during antagonist infusion in each rat. EMF of 3 $\mathrm{V}$ did not result in nerve fatigue. Responses to RNS from 2 to $10 \mathrm{~Hz}$ at this voltage were identical when performed twice at a 2 -h interval in six sham-ARF and six NE-ARF rats. Higher voltage repetitive stimulation resulted in a progressively smaller reduction in $\mathrm{RBF} / \mathrm{Hz}$ at any frequency tested. EMF of $3 \mathrm{~V}$ also did not interfere with flow probe $\mathrm{RBF}$ measurement. RBF was recorded after 2 min of stimulation with a miniature flow probe (Carolina Medical Electronics, Inc., King, NC), which was placed around the renal artery and attached to a digital recorder. The flow probe size was chosen that circumferentially fit closely about the arterial wall by low-power microscopic observation but did not alter urine flow rate. Calibration was conducted according to the method of Arendshorst et al. (17). Renal blood flow was allowed to return to baseline between stimulation periods and before measuring response to RPP reduction.

After determination of RBF response to RNS, the change in response of RBF to reduction in RPP in the autoregulatory range was measured. RPP was controlled by placing a pliable small-gauge platinum wire about the aorta above the renal artery. Alterations in RBF were determined at RPP of $120,110,100$, and $90 \mathrm{mmHg}$. Spontaneous mean arterial pressures (MAP) in sham-ARF and NE-ARF rats ranged from 118 to 126 and 120 to $131 \mathrm{mmHg}$, respectively. In those animals in which spontaneous MAP was $<120 \mathrm{mmHg}$, Ringer's lactate infusion rate was increased by up to $1.0 \mathrm{ml} / \mathrm{h}$ to achieve at least $120 \mathrm{mmHg}$ and in those in which spontaneous MAP was $>120 \mathrm{mmHg}$ it was adjusted with the aortic wire clamp. The autoregulatory range of RBF in the rat has previously been demonstrated to be between 90 and 140 $\mathrm{mmHg}(18)$. RBF was recorded $2 \mathrm{~min}$ after RPP was stabilized at each respective pressure. Measurements were made in duplicate.

Protocol 1. Intrarenal AII inhibition. Six 1-wk NE-ARF and six sham-ARF control rats infused with $0.9 \%$ saline rather than NE were prepared for RNS and RPP reduction experiments as described above. Femoral artery blood samples were obtained for inulin and $\mathrm{pH}$, sodium, potassium, calcium, and magnesium concentrations. Urine samples were obtained for inulin content. Baseline RBF followed by RBF measurements during RNS and decrements in RPP were determined. Thereafter, the renal artery infusion was changed to saralasin,
$0.1 \mu \mathrm{g} / \mathrm{kg} \cdot \mathrm{min}^{-1} .15 \mathrm{~min}$ after beginning saralasin, $\mathrm{RBF}$ responses to RNS and RPP reduction were repeated. In preliminary experiments RBF responses to RNS and RPP were measured at the maximal saralasin dose that did not reduce MAP $\left(0.2 \mu \mathrm{g} / \mathrm{Kg} \cdot \mathrm{min}^{-1}\right)$; however, the RBF response to RNS and RPP reduction was identical when a lower dose of $0.1 \mu \mathrm{g} / \mathrm{kg} \cdot \mathrm{min}^{-1}$ was infused. The latter dose was chosen to carry out subsequent combined saralasin and SQ29548 experiments described below without decreasing MAP. The inhibiting effect of saralasin was measured in a separate group of six rats where it was found that saralasin over a range of 1.0 to $4.0 \times 10^{-6} \mathrm{mmol} / \mathrm{kg} \cdot \mathrm{min}^{-1}$ infused at a more proximal site would completely block the renal vasoconstrictor effect of an equimolar infusion of AII given at a more distal site along the renal artery. The order of testing, without or with inhibitor infusion, was not randomized because of uncertainty of duration of inhibitor effect and wash out time requiring prolongation of experimental time. However, it was shown in time-control preliminary experiments that responses to RNS and RPP reduction were identical over $2 \mathrm{~h}$ which was more than the time required for the entire experiment. At the conclusion of this and all subsequent protocols kidneys were removed for determination of wet and dry weights. The latter were measured after $10 \mathrm{~h}$ in $120^{\circ} \mathrm{C}$ oven.

Protocol 2. Effect of intrarenal TXA $A_{2}$ inhibition. Experiments identical to those in protocol 1 were carried out except that SQ29548 (E. R. Squibb \& Sons, Princeton, NJ), a TXA antagonist, at 2.0 $\mu \mathrm{g} / \mathrm{kg} \cdot \mathrm{min}^{-1}$ was infused into the renal artery rather than saralasin in six NE-ARF and six sham-ARF control rats. As with saralasin, preliminary RBF responses to RNS and RPP reduction were determined at the maximal dose of SQ29548 that did not reduce MAP. The experimental dose chosen was the minimal dose that produced an effect identical to the maximal dose on RBF responses to RNS and RPP reduction in order that the combined saralasin-SQ29548 protocol could be performed without MAP reduction. As with saralasin, the inhibiting effect of SQ29548 was tested in six separate rats where a range of 1.0 to $4.0 \times 10^{-2} \mathrm{mmol} / \mathrm{kg} \cdot \mathrm{min}^{-1} \mathrm{SQ} 29548$ completely blocked the renal vasoconstrictor effect of intrarenal infusions of equimolar doses of the TXA 2 mimetic U44069 (Biomol Research Laboratories, Inc., Plymouth Meeting, PA).

Protocol 3. Effect of simultaneous AII and TXA 2 inhibition. RBF responses to RNS and RPP reduction were measured before and during combined intrarenal infusion of saralasin, $0.1 \mu \mathrm{g} / \mathrm{kg} \cdot \mathrm{min}^{-1}$, and $\mathrm{SQ} 29548,2.0 \mu \mathrm{g} / \mathrm{kg} \cdot \mathrm{min}^{-1}$, in six NE-ARF and six sham-ARF controls using the same procedure outlined in protocol 1.

Protocol 4. Effect of renal denervation. To determine the overall contribution of renal adrenergic nerve activity to the abnormal response to RPP reduction and to compare quantitatively the effect of AII and $\mathrm{TXA}_{2}$ inhibition to total interruption of renal adrenergic nerve activity, $\mathrm{RBF}$ responses to $\mathrm{RPP}$ reduction were measured before and after renal denervation in six 1-wk NE-ARF rats. Renal denervation was carried out by section of all visible branches of the renal nerves and application of $10 \%$ phenol in ethanol about the renal artery and vein as described previously (7)

Protocol 5. Renal vein norepinephrine. Six 1-wk sham-ARF and six NE-ARF rats were anesthetized and prepared for RNS experiments as described above. In addition, a small diameter polyethylene catheter was inserted via the left testicular vein into the left renal vein. A baseline collection of $200 \mu \mathrm{l}$ of blood in $1 \mathrm{~min}$ was made from the renal vein in the sham-ARF and NE-ARF rats. Thereafter, RNS was carried out as described above at $10 \mathrm{~Hz}$ for $2 \mathrm{~min}$ and a second collection of $200 \mu \mathrm{l}$ of blood was taken from the renal vein during the final minute of stimulation. The identical procedure was repeated in the same six NE-ARF rats after 15 min combined saralasin and SQ29548 infusion as in protocol 3 as well as before and after acute renal denervation in a separate group of NE-ARF rats. Blood samples were collected in heparinized capillary tubes containing solid reduced glutathione and placed on ice. The plasma was quickly separated by centrifugation, decanted, and frozen until analysis for norepinephrine concentration. Because removal of $>1 \mathrm{ml}$ of blood independently increased plasma norepinephrine concentration, simultaneous arterial samples were not taken 
with renal venous samples in these experiments. Therefore, specific secretion rates of norepinephrine were not determined. However, aortic blood samples were obtained in six sham-ARF and six NE-ARF rats before and during RNS. In the former, norepinephrine concentrations before and during RNS were $188 \pm 86$ and $206 \pm 78 \mathrm{pg} / \mathrm{ml}$ and in the latter the same respective values were $215 \pm 101$ and $234 \pm 80 \mathrm{pg} / \mathrm{ml}$. None of these values was significantly different from the other, nor was there a systematic increase in arterial norepinephrine concentration with RNS by paired analysis. Thus, norepinephrine efflux rates were considered to be a valid assessment of renal catecholamine response to RNS.

Analytical techniques and statistical analysis. Whole blood $\mathrm{pH}$ was measured with a radiometer Copenhagen $\mathrm{pH}$ meter (The London Co. Cleveland, $\mathrm{OH}$ ). Plasma sodium, potassium, calcium, and magnesium were measured by standard methodology. Plasma and urine inulin were measured with an autoanalyzer (Technicon Instruments Corp., Tareytown, NY). Plasma norepinephrine determinations were performed by the laboratory of the Clinical Research Center, University of Colorado Health Sciences Center, using the radiometric assay method described by Passon and Peuler (19). Norepinephrine efflux rate was calculated as renal plasma flow (during collection) $\times$ plasma norepinephrine concentration.

Data are expressed as means $+\mathrm{SD} . C_{\mathrm{IN}}$ and renovascular resistance (RVR) were calculated by standard equations. Linear regression analysis was used to assess the relationship between RNS or RPP and RBF. Statistical comparisons of renal blood flows before RNS or RPP reduction, slopes of RBF responses to RNS and RPP reduction, changes in $R V R$ with $R P P$ reduction and changes in renal vein norepinephrine within a single group were made by Student paired $t$ test (20). Overall comparisons between groups were made by analysis of variance (20) and individual comparisons were by Scheffe's method (21).

\section{Results}

Kidney weights and plasma electrolytes. NE-ARF kidneys appeared edematous and larger than those in sham-ARF rats. Mean group wet and dry weights of NE-ARF or sham-ARF kidneys from each protocol were similar. The mean wet weights of all NE-ARF and sham-ARF kidneys were $2.66 \pm 0.24$ and $1.42 \pm 0.21 \mathrm{~g}$, respectively $(P<0.001)$. Dry weights of these same kidneys were only slightly different $(0.63 \pm 0.14 \mathrm{~g}$ in NE-ARF and $0.42 \pm 0.12 \mathrm{~g}$ in sham-ARF, $P$ $<0.05$ ) confirming that the greater weight in the former was predominantly tissue water. The levels of blood $\mathrm{pH}$, plasma sodium, potassium, calcium, and magnesium were not different between sham-ARF and NE-ARF rats.

Effect of intrarenal AII inhibition. The respective $C_{\mathrm{IN}}$ in the sham-ARF and NE-ARF kidneys were $1.25 \pm 0.05$ and $0.38 \pm 0.23 \mathrm{ml} / \mathrm{min}$, respectively. These values were different at $P<0.001$. Saralasin had no effect on the responses to RNS or $R P P$ reduction in the sham-ARF kidneys as illustrated in Figs. 1 and 2. Baseline RBF before and during saralasin infusion and slopes of RBF to RNS and RPP reduction are shown in Table I.

In the NE-ARF rats, baseline preinfusion RBF was not different from that in sham-ARF kidneys. RBF slopes to RNS and RPP reduction were both significantly greater than the corresponding preinfusion values in sham-ARF kidneys at $P$ $<0.001$ (Figs. 1 and 2 and Table II). Baseline RBF during saralasin was similar to the preinfusion value. However, the slope of RBF to RNS was decreased significantly from the preinfusion slope at $P<0.001$. The slope of RBF to RNS during saralasin was still greater than the corresponding pre- or postinfusion value in sham-ARF kidneys at $P<0.05$. The

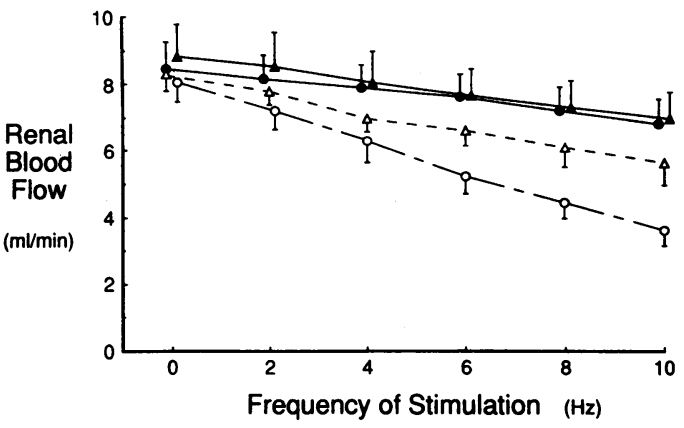

Figure 1. Renal blood flow response to renal nerve stimulation be-

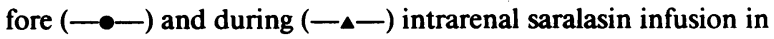
sham-ARF and before (- - $(-)$ and during $(-\Delta-)$ saralasin infusion in NE-ARF kidneys. The slope of RBF to RNS was reduced during saralasin in the NE-ARF kidneys $(P<0.001)$.

slope of RBF to RPP reduction with saralasin was less than presaralasin $(P<0.02)$, but greater than the corresponding measurement in sham-ARF kidneys $(P<0.001)$.

Mean reductions in RVR with RPP reduction in shamARF rats were similar before and during saralasin. In NE-ARF rats preinfusion $R V R$ increased by $10.08 \pm 1.12 \mathrm{mmHg}$ / $\mathrm{ml} \cdot \mathrm{min}^{-1}$. With saralasin infusion the increase in RVR was reduced to $4.64 \pm 0.88 \mathrm{mmHg} / \mathrm{ml} \cdot \mathrm{min}^{-1}(P<0.001)$. However, the RVR with saralasin in NE-ARF kidneys remained greater than in sham-ARF kidneys $(P<0.001)$.

Effect of intrarenal TXA $A_{2}$ inhibition. $C_{\mathrm{IN}}$ in the NE-ARF rats was less than half that in sham-ARF rats $(0.43 \pm 0.51$ vs. $1.11 \pm 0.14 \mathrm{ml} / \mathrm{min}, P<0.001)$. As with saralasin, SQ29548 had no detectable effect in sham-ARF kidneys as demonstrated in Figs. 3 and 4. Slopes of RBF to RNS and to RPP reduction before and during SQ29548 infusion, respectively, were not different (Table I).

In NE-ARF kidneys, preinfusion slopes of RBF to RNS and $R P P$ reduction were similar to the corresponding preinfusion values in NE-ARF rats given saralasin. With the addition of SQ29548, baseline RBF was not different from preinfusion; however, the slopes of RBF to RNS and RPP reduction were reduced compared to the corresponding preinfusion values as shown in Table I, Figs. 3 and 4. While the RBF slopes to RNS and to RPP reduction in NE-ARF kidneys were decreased

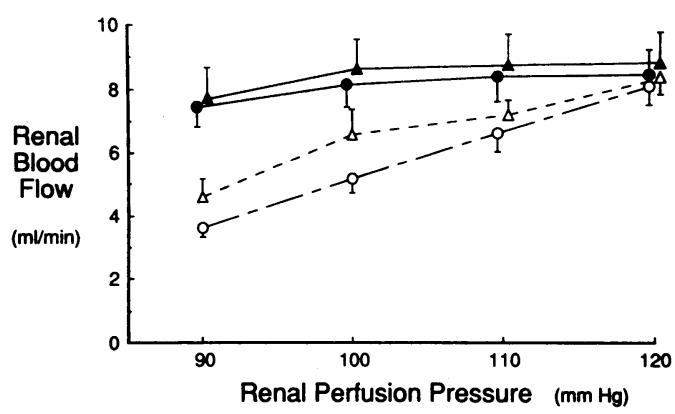

Figure 2. Renal blood flow response to renal perfusion pressure reduction before and during intrarenal saralasin infusion in sham-ARF control and NE-ARF kidneys. The slope of RBF to RPP reduction during saralasin was reduced in NE-ARF $(P<0.02)$. Respective symbols are the same as in Fig. 1. 
Table I. Renal Vein Norepinephrine Before and During RNS

\begin{tabular}{|c|c|c|c|c|c|c|c|c|c|c|}
\hline \multirow[b]{2}{*}{ Group } & \multicolumn{3}{|c|}{ Norepinephrine conc. } & \multicolumn{3}{|c|}{ Renal plasma flow } & \multicolumn{3}{|c|}{ Norepinephrine efflux } & \multirow[b]{2}{*}{ Change } \\
\hline & Before & & During & Before & & During & Before & & During & \\
\hline & \multicolumn{3}{|c|}{$p g / m l$} & \multicolumn{3}{|c|}{$\mathrm{ml} / \mathrm{min}$} & \multicolumn{3}{|c|}{$p g / m i n$} & $p g / m i n$ \\
\hline Sham-ARF [6] & $\begin{array}{c}301 \pm 115 \\
(<0.05)\end{array}$ & $(<0.05)$ & $\begin{array}{c}429 \pm 99 \\
(<0.005)\end{array}$ & $\begin{array}{c}4.26 \pm 0.36 \\
(\mathrm{~ns})\end{array}$ & $(<0.05)$ & $\begin{array}{c}3.44 \pm 0.40 \\
(<0.02)\end{array}$ & $\begin{array}{c}1282 \pm 352 \\
(<0.005)\end{array}$ & $(<0.05)$ & $\begin{array}{c}1475 \pm 333 \\
(<0.01)\end{array}$ & $\begin{array}{c}193 \pm 27 \\
(<0.001)\end{array}$ \\
\hline \multicolumn{11}{|l|}{ NE-ARF [6] } \\
\hline Control & $\begin{array}{c}527 \pm 114 \\
\text { (ns) }\end{array}$ & $(<0.005)$ & $\begin{array}{l}1402 \pm 298 \\
(<0.02)\end{array}$ & $\begin{array}{c}4.06 \pm 0.37 \\
\text { (ns) }\end{array}$ & $(<0.001)$ & $\begin{array}{c}2.26 \pm 0.31 \\
(<0.05)\end{array}$ & $\begin{array}{c}2139 \pm 321 \\
(\mathrm{~ns})\end{array}$ & $(<0.01)$ & $\begin{array}{c}3168 \pm 634 \\
(<0.05)\end{array}$ & $\begin{array}{c}1030 \pm 306 \\
(<0.001)\end{array}$ \\
\hline Sar + SQ29548 & $504 \pm 108$ & (ns) & $629 \pm 96$ & $4.25 \pm 0.26$ & $(<0.01)$ & $3.32 \pm 0.19$ & $2142 \pm 279$ & (ns) & $2088 \pm 304$ & $-54 \pm 167$ \\
\hline
\end{tabular}

Numbers in brackets are animals in study group. Data are means \pm SD. $P$ values are in parentheses. See text for abbreviations. Comparisons within a study group before and during RNS are shown horizontally between respective results and were made by paired $t$ statistics. Comparisons of respective values between study groups are shown vertically and were made by analysis of variance and Scheffe's method.

significantly by SQ29548, they remained greater than the corresponding values in sham-ARF animals.

Renovascular resistance changes before and during SQ29548 infusion in sham-ARF kidneys were not different. In NE-ARF kidneys, the increase in RVR was attenuated significantly during $\mathrm{TXA}_{2}$ antagonist infusion $(P<0.001)$. However, the RVR during infusion remained greater than in sham-ARF kidneys $(P<0.001)$.

Effect of simultaneous $A I I$ and $T X A_{2}$ inhibition. The $C_{\mathrm{IN}}$ levels in sham-ARF and NE-ARF kidneys were $1.02 \pm 0.30$ and $0.34 \pm 0.20 \mathrm{ml} / \mathrm{min}$, respectively, different at $P<0.001$. The respective $C_{\mathrm{IN}}$ levels in the sham-ARF and NE-ARF kidneys were not different from those measured in the saralasin or SQ29548-only infusion protocols. Baseline RBF and slopes of RBF to RNS and RPP reduction in the sham-ARF rats before and during saralasin + SQ29548 were similar as illustrated in Figs. 5 and 6 and specified in Table $I$.

In NE-ARF rats baseline RBF before and during saralasin + SQ29548 infusion were not different. While comparative slopes to RPP reduction between sham-ARF and NE-ARF after saralasin + SQ29548 remained different at $P<0.001$, those to RNS were similar (Figs. 5 and 6 and Table I). The decreases in RBF slopes to RNS and RPP reduction with combined saralasin + SQ29548 were both significantly greater than those with either saralasin or SQ29548 given alone (both $P<0.02)$.

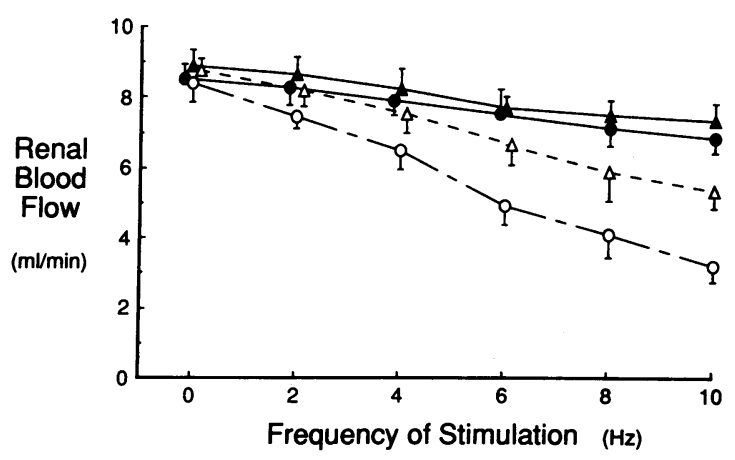

Figure 3. Renal blood flow response to renal nerve stimulation before and during intrarenal SQ29548 infusion in sham-ARF control and NE-ARF kidneys. The slope of RBF to RNS was reduced during SQ29548 in NE-ARF kidneys $(P<0.01)$. Respective symbols are the same as in Fig. 1.
Changes in RVR with RPP reduction were not different before and during saralasin + SQ29548 in sham-ARF kidneys. In NE-ARF kidneys the preinfusion $R V R$ was $+12.86 \pm 0.80$ $\mathrm{mmHg} / \mathrm{ml} \cdot \mathrm{min}^{-1}$; however, during infusion it was reduced to $+1.78 \pm 0.28 \mathrm{mmHg} / \mathrm{ml} \cdot \mathrm{min}^{-1}(P<0.001)$. The increase in this latter value was significantly less than that with infusion of only saralasin or SQ29548 (both $P<0.01$ ); however, it remained significantly different from the corresponding $R V R$ in sham-ARF rats.

Effect of renal denervation. Renal blood flow responses to RPP reduction in NE-ARF with acute renal denervation are shown in Fig. 7. After denervation, baseline RBF was not significantly greater than the predenervation value; however, the slope of RBF to RPP reduction and corresponding RVR were reduced substantially as indicated in Table $\mathrm{I}(P<0.001)$.

The postdenervation slope of RBF to RPP reduction and RVR, while less than the same respective values in NE-ARF rats during either saralasin or SQ29548 alone, were similar to those during combined saralasin and SQ29548 infusion.

Renal vein norepinephrine. The concentrations of renal venous plasma norepinephrine concentrations and efflux rates are shown in Table I. Baseline norepinephrine efflux rates were elevated in NE-ARF compared to sham-ARF rats. The absolute increase in efflux rate during RNS was significantly greater in the NE-ARF group $(P<0.01)$. The prestimulation norepinephrine efflux rate did not change detectably during saralasin

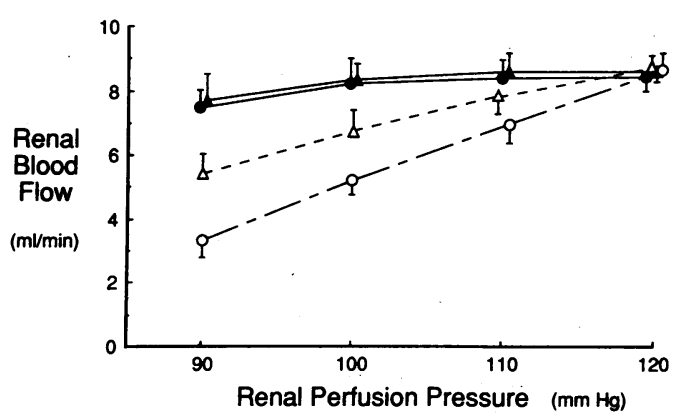

Figure 4. Renal blood flow response to renal perfusion pressure reduction before and during intrarenal SQ29548 infusion in shamARF control and NE-ARF kidneys. The slope of RBF to RPP reduction was reduced during SQ29548 in NE-ARF kidneys $(P<0.02)$. Respective symbols are the same as in Fig. 1. 
+ SQ29548 infusion in the NE-ARF group. During RNS, there was no increase in norepinephrine efflux with saralasin + SQ29548 which was significantly different from the response before AII and TXA inhibition $(P<0.001)$.

Renal venous norepinephrine efflux was also measured rate was $556 \pm 102$ before and $305 \pm 58 \mathrm{pg} / \mathrm{min}$ after denervation. These values were different by paired analysis at $P<0.02$.

\section{Discussion}

Adams et al. (4), Matthys and associates (5), and Conger (6) demonstrated that there was a loss of RBF autoregulation in experimental ischemic ARF. In subsequent experiments it was found that the pattern of $R B F$ response to RPP reduction was not that of functionally unresponsive renal resistance vessels; but rather, there was a striking paradoxical increase in RVR as RPP was lowered in the autoregulatory range (7). Moreover, denervation of the kidney, while not restoring normal RBF autoregulation, obliterated the vasoconstriction to decreases in RPP (7). A potential role for accelerated renal adrenergic nerve activity in recurrent ischemic injury in the maintenance phase of NE-ARF was supported by experiments in which renal denervation was carried out before transient reduction in RPP. Unlike rats with intact renal nerves, those with renal denervation had neither recurrent increases in blood urea nitrogen or serum creatinine nor new ischemic lesions in the kidneys (22). These data appeared to implicate enhanced response to adrenergic nerve impulses in the abnormal vascular sensitivity to RPP manipulation in established ischemic ARF.

The present study was carried out to investigate the mechanism of hypersensitivity to RNS. Two parallel observation suggested roles for angiotensin and thromboxane. First, reninangiotensin and thromboxane activity are known to be increased after ischemic injury to the kidney. Several investigators have measured increases in plasma and renal renin activity in clinical and experimental ARF $(13,14,23-25)$. Others have provided evidence that renal thromboxane activity is elevated after ischemia $(15,26)$. The second related observation is that AII and TX are known to potentiate RNS-induced vasoconstriction $(8-10,12,27,28)$. While angiotensin has been shown to enhance and thromboxane synthetase inhibition to decrease vasoconstriction to RNS, these agents have had little effect on the response to infused NE $(8,12)$, suggesting that the major effect of angiotensin and thromboxane is to potentiate the release of neurotransmitter. In the present study no attempt was made to measure renal angiotensin; however, it was clear that intrarenal infusion of saralasin in doses that blocked the effects of equimolar doses of exogenous AII significantly attenuated the RBF decline to RNS in ARF rats indicating that AII was at least partially responsible for the adrenergic vascular hypersensitivity. A similar partial reduction in RBF response to RNS in ARF rats was found with a dose of SQ29548 that inhibited the $\mathrm{TXA}_{2}$ mimetic U44069. The combined inhibi-

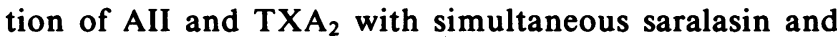
SQ29548 infusion, which had an additive effect, obliterated the adrenergic nerve hypersensitivity of the renal vasculature. While the study was designed so that there was no effect of inhibitors on basal renal hemodynamics, it is of interest that the doses chosen attenuated the responses to RNS and RPP reduction in ARF kidneys without altering basal RBF or RVR in either study group. before and after renal denervation in NE-ARF kidneys. Efflux

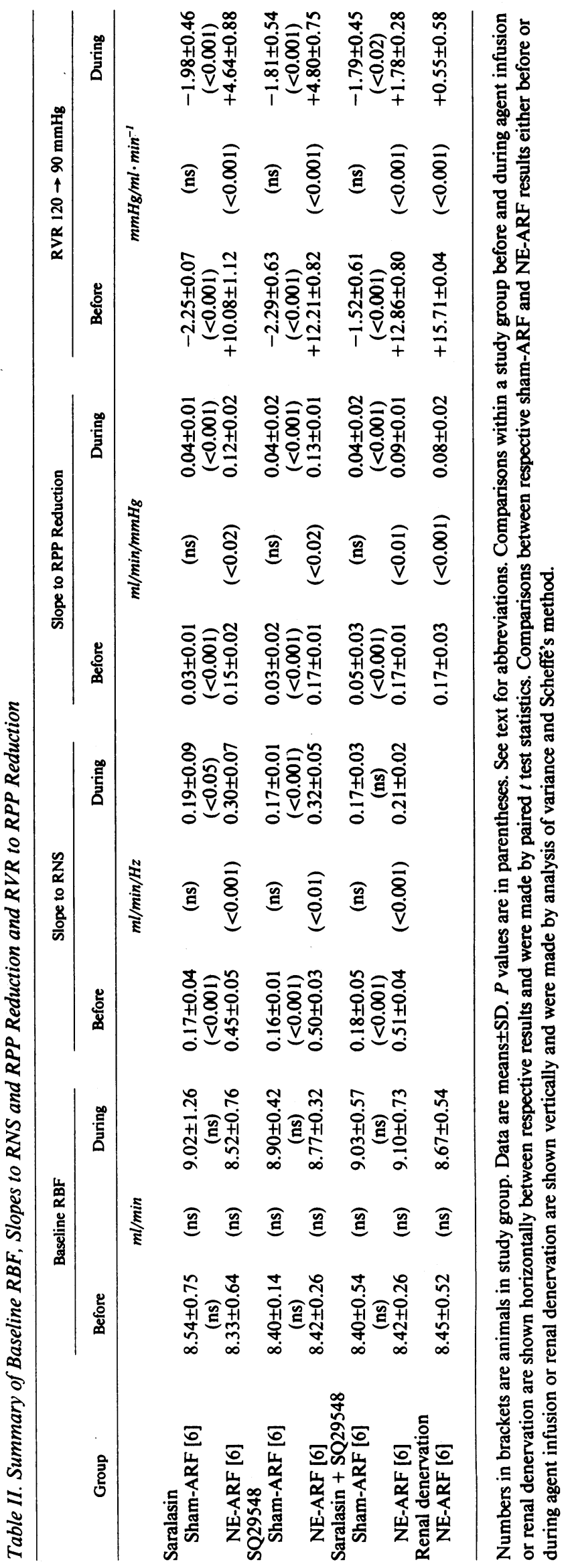




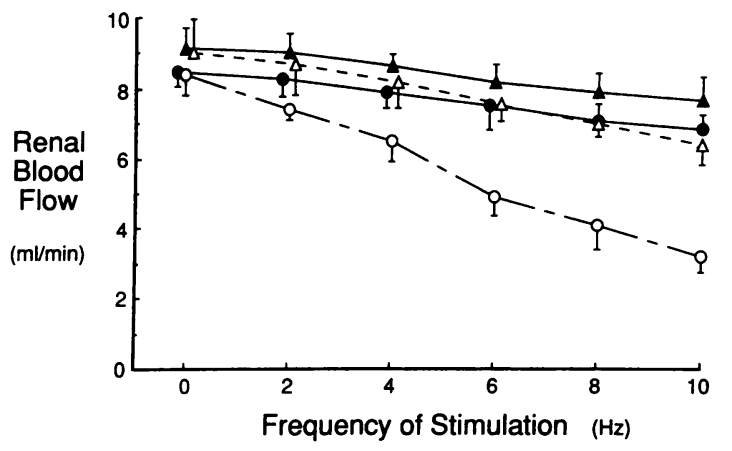

Figure 5. Renal blood flow response to renal nerve stimulation before and during combined intrarenal saralasin and SQ29548 infusion in sham-ARF control and NE-ARF kidneys. The combined infusion reduced the slope of $R B F$ to RNS more than with either agent alone $(P<0.02)$ in NE-ARF kidneys and to the same slope as sham-ARF control kidneys. Respective symbols are the same as in Fig. 1.

It is unlikely that the attenuation of hypersensitivity to RNS by saralasin and SQ29548 was due to a vasodilator or other nonspecific vascular effect. In a previous study it was shown that prostacyclin-induced vasodilation was normal in 1 wk NE-ARF kidneys; however, it did not reduce the RBF slope to RNS or RPP reduction (29). Moreover, a combination of AII receptor antagonist and the thromboxane synthetase inhibitor, OKY 046, also has been reported to eliminate hypersensitivity to RNS in NE-ARF (30).

The results of renal venous norepinephrine measurements were compatible with a potential role for angiotensin and thromboxane in augmenting catecholamine release in response to RNS. While venous norepinephrine efflux measurements were less desirable than actual kidney catecholamine secretion rates, the latter were difficult to obtain because the required volume sample increased plasma norepinephrine concentration. Thus, norepinephrine efflux was considered to be a valid compromise in assessing renal catecholamine activity, because it was determined that neither ARF at 1 wk or RNS increased arterial norepinephrine concentration. The greater increase in norepinephrine efflux with RNS was in all likelihood due to an enhanced release from intrarenal nerve

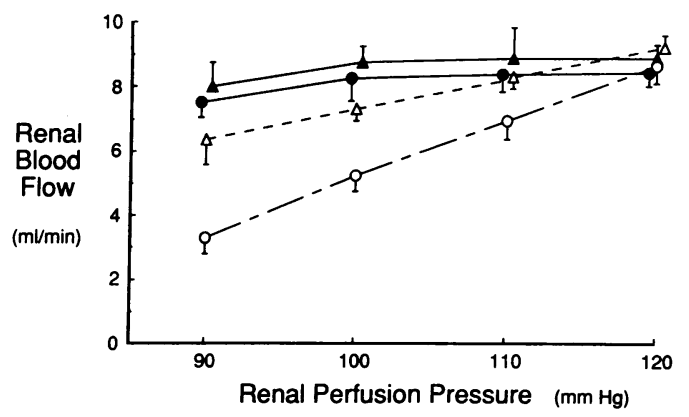

Figure 6. Renal blood flow response to renal perfusion pressure reduction before and during combined intrarenal saralasin and SQ29548 infusion in sham-ARF control and NE-ARF kidneys. The combined infusion reduced the slope of RBF to RPP reduction in NE-ARF kidneys more than with either agent alone $(P<0.02)$ but was still greater than that in sham-ARF kidneys $(P<0.01)$. Respective symbols are the same as in Fig. 1.

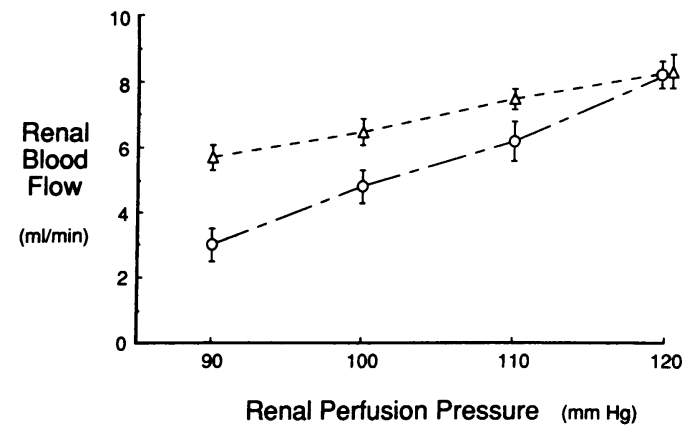

Figure 7. Renal blood flow response to renal perfusion pressure reduction before $(-\infty-)$ and after $(-\Delta-)$ renal denervation in NEARF kidneys. The slope of RBF to RPP reduction following renal denervation was identical to that during combined saralasin and SQ29548 infusion.

terminals. The attenuated norepinephrine efflux with the same RNS frequency in the same animals during saralasin and SQ29548 infusion strongly supports the possibility that AII and $\mathrm{TXA}_{2}$ quantitatively increase norepinephrine release to RNS in ARF kidneys. These data do not, however, exclude the possibility that angiotensin or thromboxane may have an additional role at a site beyond the nerve terminal to enhance the renovascular response to RNS.

How does the correction of hypersensitivity to RNS by AII and $\mathrm{TXA}_{2}$ inhibition relate to the effects of saralasin and SQ29548 on the abnormal vasoconstriction to RPP reduction in NE-ARF? Combined saralasin and SQ29548 had a similar effect on the RBF response to RPP reduction as renal denervation, i.e., while paradoxical vasoconstriction was blocked, an appropriate autoregulatory vasodilatation response did not occur. It can be inferred, therefore, that there are at least two mechanistic components of the abnormal RBF autoregulation in NE-ARF: First, the paradoxical vasoconstriction to RPP reduction mediated by $\mathrm{AII}$ and $\mathrm{TXA}_{2}$-induced adrenergic nerve hypersensitivity and, secondly, the inability of the kidney vasculature to vasodilate appropriately to myogenic or tubuloglomerular feedback stimuli.

While the results of the present study identify a mechanism of exaggerated response to adrenergic nerve activity, they do not address the actual changes in renal nerve impulses with manipulation of renal perfusion pressure. Little is known about renal afferent and efferent nerve activity with controlled reductions in RPP and there are no studies addressing this issue in ARF. A recent report by Moss (31) indicated that RPP reduction to $80 \mathrm{mmHg}$ in the normal rat stimulates afferent nerve activity by an $R_{2}$ chemoreceptor mechanism. The increased afferent nerve impulses related to RPP reduction, in turn, have been shown to increase efferent renal nerve activity (32). It is reasonable to assume that in the present study decreasing RPP directly or by reflex mechanisms increases or, at least, does not decrease renal efferent nerve activity. Reduction in RPP by aortic constriction in the present study likely increased arterial pressure above the constriction independently modifying efferent renal nerve impulses by a reflex mechanism (33). Changes approaching $100 \%$ in efferent impulse rate under normal physiologic conditions have a negligible effect on RBF (34). Thus, while the presumed net increase in efferent nerve activity with RPP reduction was not quanti- 
fied, the data indicate that AII and $\mathrm{TXA}_{2}$ activity were required to amplify the neuroeffector response in the kidney. Moreover, even at the same impulse frequency generated by RNS, the vasoconstriction in NE-ARF kidneys was greater than that in control kidneys.

The abnormal autoregulation response in NE-ARF not related to renal nerve activity was not specifically examined in the present experiments. However, some of the data from this and other studies in established postischemic ARF at least indirectly address this problem. The common characteristic of the residual component of abnormal autoregulation in the saralasin + SQ29548 infused and denervated kidneys was the absence of decrease in RVR with reduction of RPP in the autoregulatory range. Thus, free of major adrenergic nerve influence, the resistance arterial vessels in the kidney had reduced physiologic sensitivity. Whereas this observation might suggest that the initial hemodynamic event that induced ARF 1 wk previously also caused sustained ischemic injury of vascular smooth muscle (5), the responsiveness to renal nerve stimulation would argue against this. Therefore, it is more likely that the lack of change in RVR in the absence of exaggerated renal nerve activity represents failure of the control mechanism that mediates vasodilatation to RPP reduction. Because the precise mechanism of vasorelaxation to reduced vessel lumen pressure remains undetermined, it is not possible to identify the defect in this mechanism that occurs in NEARF. Recent studies have shown that endothelium-derived relaxing factor (EDRF) activity is depressed after ischemia (29, $35,36)$. This observation suggests the possibility that EDRF may play a role in mediating pressure reduction related vasorelaxation and, in its absence, appropriate vasodilatation may not occur. There is also indirect evidence that ischemic injury to the kidney results in calcium leak into smooth muscle cells (29). Thus, an alternative potential mechanism for impaired vasorelaxation to pressure reduction is the inability of messengers (such as EDRF) to attenuate entry of calcium into vascular smooth muscle cells.

It is interesting to note that in previous studies where abnormal autoregulation was observed 1-7 d after renal artery clamping of 90 and $40 \mathrm{~min}$ in $\operatorname{dog}(4)$ and rat (5), respectively, a paradoxical vasoconstriction to RPP reduction was not observed. Rather, there was an absence, or near absence, of change in RVR as was seen in the present study with renal denervation or saralasin + SQ29548 infusion. While a possible explanation for the different response pattern to RPP reduction is renal nerve injury from the renal artery clamp, recent data from our laboratory suggest that the differences in RBF responses to RPP reduction in the NE-induced and renal artery clamp models may be more complex. It was determined that $\mathrm{RBF}$ during NE-induced ischemia was between 0.8 and $1.0 \mathrm{ml} / \mathrm{min}$, whereas, in a 75-min renal artery clamp model in uninephrectomized rats that had the same level of renal dysfunction at $1 \mathrm{wk}$ it was only 50-60 $\mu \mathrm{l} / \mathrm{h}$ (37). Thus, the renal artery clamp is a more complete initial ischemia model and may cause injury to vascular smooth muscle as suggested by the morphology studies of Matthys et al. (5). It is possible that vascular smooth muscle cell necrosis is sufficiently severe that the renal vasculature would be unresponsive to any vasoactive stimulation and thus would show a different pattern of RBF response to RNS than was seen with the incomplete ischemia model used in the present study.

\section{Acknowledgments}

We would like to thank Barbara C. Falk for her expert help in the preparation of this manuscript and Carol Bauer for her excellent technical help in catecholamine measurements.

This work was supported by National Institutes of Health grant DK 35098 and Veterans Administration merit review funds.

\section{References}

1. Reubi, F. C., C. Vorburger, and J. Tuckman. 1973. Renal distribution volumes of indocyanine, ${ }^{51} \mathrm{Cr}$-EDTA and ${ }^{24} \mathrm{Na}$ in man during acute renal failure. J. Clin. Invest. 52:223-235.

2. Conger, J. D., J. B. Robinette, and S. P. Kelleher. 1984. Nephron heterogeneity in ischemic acute renal failure. Kidney Int. 36:422-429.

3. Cox, J. W., R. W. Baehler, H. Sharma, T. O'Dorisio, R. W. Osgood, J. H. Stein, and T. F. Ferris. 1974. Studies on the mechanism of oliguria in a model of unilateral acute renal failure. J. Clin. Invest. 53:1546-1558.

4. Adams, P. L., P. F. Adams, P. D. Bell, and L. G. Navar. 1980. Impaired renal blood flow autoregulation in ischemic acute renal failure. Kidney Int. 18:68-76.

5. Matthys, E., M. Patton, R. Osgood, M. Venkatachalam, and J. Stein. 1983. Alterations in vascular function and morphology in ischemic ARF. Kidney Int. 23:717-724.

6. Conger, J. D. 1983. Vascular abnormalities in the maintenance of acute renal failure. Circ. Shock. 11:235-244.

7. Kelleher, S. P., J. B. Robinette, and J. D. Conger. 1984. Sympathetic nervous system in the loss of autoregulation in acute renal failure. Am. J. Physiol. 246:F379-386.

8. Zimmerman, B. G., and J. Gisslen. 1968. Pattern of renal vasoconstriction and transmitter release during sympathetic stimulation in presence of angiotensin and cocaine. J. Pharmacol. Exp. Ther. 163:320-329.

9. Johnson, E. M., Jr., G. R. Marshall, and P. Needleman. 1974. Modification of responses to sympathetic nerve stimulation by the renin-angiotensin system in rats. Br. J. Pharmacol. 51:541-547.

10. Needleman, P., G. R. Marshall, and E. M. Johnson, Jr. 1974. Determinants and modification of adrenergic and vascular resistance in the kidney. Am. J. Physiol. 227:665-669.

11. Zimmerman, B. G. 1978. Actions of angiotensin on adrenergic nerve endings. Fed. Proc. 37:199-202.

12. Jackson, E. K., H. D. Uderman, W. A. Herzer, and R. A. Branch. 1984. Attenuation of noradrenergic neurotransmission by the thromboxane synthetase inhibitor, UK 38,485. Life Sci. 35:221-228.

13. Hayes, J. M., J. M. D. O'Connell, L. Siegel, F. H. Pryce, and G. E. Schreiner. 1968. Renal renin and renin release in acute renal failure in the rat. Fed. Proc. 27:629-632.

14. DiBona, G. F., and L. L. Sawin. 1971. The renin-angiotensin system in acute renal failure in the rat. Lab. Invest. 25:528-532.

15. Hatziantoniou, C., and N. Papanikolaou. 1986. Renal effects of the inhibitor of thromboxane $A_{2}$-synthetase OKY-046. Experientia (Basel). 42:613-615.

16. Conger, J. D., J. B. Robinette, and S. J. Guggenheim. 1981. Effect of acetylcholine on the early phase of reversible norepinephrine-induced acute renal failure. Kidney Int. 19:399-409.

17. Arendshorst, W. J., W. F. Finn, and C. G. Gottschalk. 1979. Autoregulation of renal blood flow in the rat. Circ. Res. 44:344-349.

18. Conger, J. D., and T. J. Burke. 1976. Effects of anesthetic agents on autoregulation of renal hemodynamics in the rat and dog. Am.J. Physiol. 230:652-657.

19. Passon, P. G., and J. D. Peuler. 1973. A simplified radiometric assay for plasma norepinephrine and epinephrine. Anal. Biochem. 51:618-631.

20. Snedecor, G. W., and W. G. Cochran. 1980. Statistical Methods. Iowa State University Press, Ames, IA. 221-339. 
21. Wallenstein, S., C. L. Zucker, and J. L. Fleiss. 1980. Some statistical methods useful in circulation research. Circ. Res. 47:1-9.

22. Kelleher, S. P., J. B. Robinette, F. Miller, and J. D. Conger 1987. Effect of hemorrhagic reduction in blood pressure on recovery from acute renal failure. Kidney Int. 31:725-730.

23. Vertel, R. M., and J. P. Knochel. 1967. Non-oliguric acute renal failure. JAMA (J. Am. Med. Assoc.). 200:598-602.

24. Kokot, F., and J. Kuska. 1969. Plasma renin activity in acute renal insufficiency. Nephron. 6:115-127.

25. Brown, J. J., D. L. Davies, A. F. Lever, R. A. Parker, and J. I. S. Robertson. 1966. The assay of renin in single glomeruli and the appearance of the juxtaglomerular apparatus following renal artery constriction. Clin. Sci. 30:223-235.

26. Oken, D. E., M. L. Arce, and D. R. Wilson. 1966. Glycerol-induced hemoglobinuric acute renal failure in the rat. I. Micropuncture study of the development of oliguria. J. Clin. Invest. 45:724-735.

27. Hughes, J., and R. H. Roth. 1971. Evidence that angiotensin enhances transmitter release during sympathetic nerve stimulation. $\mathrm{Br}$. J. Pharmacol. 41:239-255.

28. Zimmerman, B. G., and L. Whitmore. 1967. Effect of angiotensin and phenoxybenzamine on release of norepinephrine in vessels during sympathetic nerve stimulation. Int. J. Neuropharmacol. 6:27-38.

29. Conger, J. D., J. B. Robinette, and R. W. Schrier. 1988. Smooth muscle calcium and endothelium-derived relaxing factor in the abnormal vascular responses of acute renal failure. J. Clin. Invest. 82:532537.
30. Conger, J. D., and J. B. Robinette. 1989. Hypersensitivity to renal nerve stimulation in acute renal failure due to thromboxane and angiotensin. Kidney Int. 35:404a. (Abstr.)

31. Moss, N. G. 1987. Electrophysiological characteristics of sensory mechanisms in the kidney. Clin. Exp. Hypertens. Part A Theory Pract. 9:1-13.

32. Fater, J. E. 1987. Inhibitory effect of the contralateral kidney on the renal pressor reflex evoked by ipsilateral renal artery stenosis. Clin. Exp. Hypertens. Part A Theory \& Pract. 9:241-257.

33. Fink, G. D., and M. J. Brody. 1980. Impaired neurogenic control of renal vasculature in renal hypertensive rats. Am. J. Physiol. 238:H770-H775.

34. Zambraski, E. J., E. H. Prosnitz, and G. F. DiBona. 1978. Lack of evidence for renal vasodilatation in anesthetized dogs. Proc. Soc. Exp. Biol. Med. 158:462-465.

35. Van Benthuysen, K. M., I. F. McMurty, and L. D. Horwitz. 1987. Reperfusion after acute coronary occlusion in dogs impairs endothelium-dependent relaxation to acetylcholine and augments contractile reactivity in vitro. J. Clin. Invest. 79:265-274.

36. Altiere, R. J., J. W. Olson, and M. N. Gillespie. 1986. Altered pulmonary vascular smooth muscle responsiveness in monocrotalineinduced pulmonary hypertension. J. Pharmacol. Exp. Ther. 236:390395.

37. Robinette, J. B., and J. D. Conger. 1990. Differences in vascular reactivity in acute renal failure induced by complete and incomplete ischemia. Kidney Int. 37:493a. (Abstr.) 